\title{
Changes in euro area monetary transmission?
}

\author{
Axel A. Weber ${ }^{a, *}$ \\ Rafael Gerke ${ }^{a, b, *}$ \\ Andreas Worms ${ }^{\text {a, * }}$ \\ ${ }^{a}$ Deutsche Bundesbank, Wilhelm-Epstein-Straße 14, 60431 Frankfurt am Main, Germany

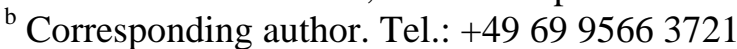 \\ Email address: rafael.gerke@bundesbank.de
}

August 2008

\begin{abstract}
Empirical evidence on whether euro area monetary transmission has changed is, at best, mixed. We argue that this inconclusiveness is likely to be due to the fact that existing empirical studies concentrate on the effects of particular developments on specific transmission channels. Such analyses typically require strong assumptions. Moreover, specific changes could have off-setting effects regarding the overall effectiveness of monetary policy. In order to shed light on this issue, we investigate whether there has been a significant change in the overall transmission of monetary policy to inflation and output by estimating a standard VAR for the euro area and by endogenously searching for possible break dates. We find a significant break point around 1996 and some evidence for a second one around 1999. We compare the effects of monetary policy shocks for these episodes and find that the wellknown "stylized facts" of monetary policy transmission remain valid. Therefore, we argue that the general guiding principles of the Eurosystem monetary policy remain adequate. Moreover, it seems that monetary transmission after 1998 is not very different from before 1996, but probably very different compared to the interim period. This implies that existing evidence for the euro area could be biased by this "atypical" interim period 1996-1999.
\end{abstract}

JEL classification: E44, E52, E58, G21

Keywords: Monetary policy transmission, Eurosystem, euro area, globalisation, financial development, VAR

\footnotetext{
*) The views expressed in this paper are not necessarily those of the Deutsche Bundesbank. We appreciate helpful comments and suggestions by Jörg Breitung, Christina Gerberding, Stefan Gerlach, Felix Hammermann, Wolfgang Lemke, Manfred J. M. Neumann and Ralph Setzer. We benefited from insightful discussions on an earlier version of this paper at the $7^{\text {th }}$ BIS Annual Conference, in particular we are grateful to Arminio Fraga Neto, Ben Friedman, Marvin Goodfriend, Charles Goodhart, Otmar Issing, Mervyn King, Ulrich Kohli, Christopher Sims, Christian Upper, Ignazio Visco and Michael Woodford. We thank seminar participants at the ROME workshop in Frankfurt, the Erich Schneider seminar in Kiel and our discussant Stefano Siviero at "Monetary policy transmission mechanism in the euro area in its first 10 years," European Central Bank, Frankfurt. All remaining errors and shortcomings are of course our own.
} 


\section{Introduction}

The possibility that key economic structures could have undergone significant changes in recent years is currently being discussed intensively among academics and policymakers. Examples are the ongoing debates on the stability of money demand, on the sometimes suspected breakdown of the money-inflation nexus in several countries or on the reliability of estimated Phillips curves.

Of course, this is a key issue from a monetary policy perspective as the implications of such changes for the transmission process could have serious consequences, e.g. for the selection of indicators used to assess the stance of monetary policy, for the design of the monetary policy strategy and even for the overall orientation of monetary policy. Immediately three main developments come to mind as potential causes for such changes: financial development, globalisation, and - in the case of the euro area - the creation of the European Monetary Union (EMU), but other factors could be at play as well. Whether and how overall monetary transmission to output and prices has been altered by all these factors cannot be answered on a theoretical basis alone but has to be addressed empirically.

Unfortunately, most of the related empirical literature does not analyse whether overall monetary transmission to output and prices in the recent decade was subject to any change. Rather, this literature concentrates on specific transmission channels and asks whether specific factors have changed the working or the (relative) importance of these channels: ${ }^{1}$

- While deeper, more complete and more competitive financial markets tend to speed up the interest rate pass-through (e.g., Leuvensteijn, Kok Sørensen, Bikker and van Rixtel, 2008; de Bondt, 2005; de Bondt, Mojon and Valla, 2005; Gropp, Kok Sørensen and Lichtenberger, 2007), globalisation and increased financial openness of many countries could have eroded monetary policy's influence on national long-term interest rates (see, inter alia Deutsche Bundesbank, 2007; Upper and Worms, 2003; Boivin, Giannoni and Mojon, 2008).

1 This list is probably not exhaustive as there might be other channels at work. Some of these, e.g. the risktaking channel of monetary policy (Borio and Zhu, 2007) have up to now not been examined in greater detail. For a more detailed literature review, see Cournède, Ahrend and Price (2008) or Weber, Gerke, and Worms (2008). 
- While the creation of EMU should per se have weakened the exchange rate channel of monetary transmission for the euro area countries - because, compared to the situation prior to 1999, the euro area has become a comparatively closed economy since a large share of trade now remains within EMU - globalisation by increasing cross-border production and international trade linkages could ceteris paribus have heightened the relative importance of the exchange rate in the economy (Deutsche Bundesbank, 2007; Mishkin, 2008). However, there is little empirical evidence for the euro area on possible changes of the exchange rate channel in recent years.

- Financial development should have reduced the importance of the bank lending channel because it increased banks' flexibility to react to (restrictive) monetary policy (see e.g. Altunbas, Gambacorta and Marqués, 2007) and moreover reduced the dependency of borrowers on banks. However, the bank lending channel could have been strengthened by financial development as well, namely by weakening those factors that have led to a weak bank lending channel in the first place. ${ }^{2}$

- Financial liberalization and innovation have generally facilitated the access of standardized credit to borrowers. As a result, the importance of asset prices for collateral purposes and hence for lending has likely increased, possibly fostering the balance sheet channel. On the other side, consolidation in the banking industry could have lowered the importance of collateral and thereby of the balance sheet channel if the resulting larger institutions can employ superior technologies to assess borrower risk. Moreover, consolidation could have enhanced this channel if it implies that locally active institutions have become less important and institutional knowledge about local conditions and local borrowers got lost.

- Some recent empirical work points to a flattening of the Phillips curve, that is, a weaker relationship between the domestic output gap and lagged and/or expected price development on the one side and domestic inflation on the other. One argument in this context is that globalisation made domestic inflation less responsive to the domestic

2 For instance, in the case of Germany, the apparent weakness of the bank lending channel can be traced back to the institutional structure of the German banking system and the long-term relationships between banks and customers which tend to entail an implicit insurance of the credit customer against adverse shocks, such as a restrictive monetary policy (Ehrmann and Worms, 2004). If financial development increases competition between banks but also between banks and other financial market segments, then 
output gap and more dependent on worldwide capacity utilisation (Borio and Filardo, 2007; Deutsche Bundesbank, 2007; Ihrig, Kamin, Lindner and Marquez, 2007; Musso, Stracca and van Dijk, 2007). ${ }^{3}$ However, for the euro area, Borio and Filardo (2007) and Calza (2008) provide only little evidence that global capacity constraints have either explanatory or predictive power for domestic consumer price inflation. Another argument in favour of a flatter Philips-curve is that monetary policy has become more credible in recent years so that inflation shocks affect inflation expectations and future inflation much less than they did before (Mishkin, 2008; Ihrig, Marazzi and Rothenberg, 2006; Pain, Koske and Sollie, 2006; Ball,2006).

All in all, the evidence clearly suggests that different forces are at play. But taken together, it remains an open issue whether the overall strength and dynamics of monetary transmission to output and inflation has changed at all in the euro area. Because of two reasons, this inconclusiveness is rooted in the fact that these studies focus either on specific transmission channels and/or on single causing factors. One is that the empirical identification of a change in a particular transmission channel caused by a specific factor is very demanding as it requires both, the empirical identification of the transmission channel of interest and the empirical isolation of the driving factor from other potential influences. This is really a daunting task as the transmission channels as well as the factors that potentially drive the changes are interrelated. Ultimately, it comes to no surprise that some of these papers find mixed or even contradicting results on the same (narrow) issue (e.g. the role of globalisation on the Phillips curve). The other aspect is that concentrating too much on specific channels and single causes does not allow conclusions about the development of the overall effectiveness of monetary policy. This argument is even more important if one considers that globalisation, financial development, the creation of EMU and any other factor are likely to interact, so that they could in principle reinforce or weaken each other with regard to their overall effect on monetary transmission.

Therefore, the route we take mainly differs in two dimensions. (1) instead of assuming a break date based on reflections about a single causing factor, we endogenously search for potential break points in monetary transmission independent of any specific

this so-called "housebank principle" could loose importance, thereby ceteris paribus strengthening the bank lending channel.

3 Note, Sbordone (2007) and Woodford (2007) argue that such changes are not likely to be large. 
cause and (2) instead of concentrating on particular transmission channels, we check whether or not monetary transmission to output and inflation as a whole has changed. To do so, we estimate a fairly standard VAR for the euro area and check whether there have been notable changes in the general way monetary policy shocks affect output and inflation. More specifically, instead of assuming a specific break date, we first apply a data-driven (agnostic) search for such a date. We find evidence for a significant break point around 1996 and evidence for a second one around 1999. Then, we compare impulse responses (IRFs) to a monetary policy shock for the resulting sub-periods and find that monetary transmission looks significantly differently in the middle period 1996-1998, while we do not find significant differences in the endogenous responses to a monetary policy shock between the period before 1996 and the period after 1998. We interpret this as evidence in favour of an "atypical interim period".

All in all, while we document breaks in monetary transmission (which, at first sight, would tend to make monetary policy more difficult and uncertain) our result of no significant difference between the transmission process before 1996 and after 1998 is generally reassuring. It implies that the monetary transmission process in the euro area is not really different from what we have observed, say, in the 1980s and early 1990s. We summarise the results and draw some conclusions in Section 4.

\section{A VAR model for the euro area}

\subsection{VAR specification}

Our baseline VAR specification can be written in matrix form as

$$
y_{t}=k+A(L) y_{t-1}+B x_{t}+u_{t}
$$

$y_{t}$ is the vector of endogenous variables, $k$ the vector of constants, $x_{t}$ the vector of exogenous variables and $u_{t}$ is the vector of serially uncorrelated disturbances that have a zero mean and a time invariant covariance matrix. $A(L)$ denotes a matrix polynomial in the lag operator $L$ and $B$ is a coefficient matrix. In our baseline specification, the vector of endogenous variables $y_{t}$ consists of four euro area variables: real GDP $\left(g d p_{t}\right)$, the 
GDP deflator $\left(p g d p_{t}\right)$, an indicator for real housing wealth (hhwreal $\left.{ }_{t}\right)$ and a domestic nominal short-term interest rate $r s_{t}$ (for a similar specification see, for instance, Iacoviello (2005)):

$$
y_{t}^{\prime}=\left(\begin{array}{llll}
g d p_{t} & p g d p_{t} & \text { hhwreal } & r s_{t}
\end{array}\right) .
$$

The vector of exogenous variables contains a non-oil commodity price index $\left(\mathrm{pcm}_{t}\right)$ and a US short-term interest rate $\left(\right.$ usrs $\left._{t}\right)$ :

$$
x_{t}^{\prime}=\left(\begin{array}{cc}
p_{t} & u^{\prime} r s_{t}
\end{array}\right) \text {. }
$$

The exogenous variables are included mainly in order to avoid a potential "price puzzle” (i.e., a price increase following an interest rate tightening) that is widespread in the empirical VAR literature. By treating these variables as exogenous, we allow for a contemporaneous impact of the exogenous on the endogenous variables, but not for a feedback (see also Peersman and Smets, 2003).

We use standard information criteria to determine the lag length of the VAR. Based on the Hannan-Quinn (HQ) and the Schwarz criterion (SC) the lag order turns out to be two. ${ }^{4}$ We identify monetary policy shocks by a standard Choleski-decomposition with the variables ordered as in (2). This implies that monetary policy shocks do not have a contemporaneous impact on output, prices and housing wealth but allows for a contemporaneous reaction of monetary policy to all other variables of the system. However, varying the ordering does not affect the results significantly (see also Assenmacher-Wesche and Gerlach, 2008). Moreover, using the more agnostic sign restriction approach of Uhlig (2005) corroborates that the triangular Choleski identification scheme is reasonable.

The VAR model is estimated in levels, using quarterly data over the period 1980:12006:4. All variables except the interest rates are transformed to logarithms. ${ }^{5}$ We use a three-month interest rate as the monetary policy instrument. GDP and the GDP deflator

\footnotetext{
4 We disregard the Akaike criterion as it asymptotically overestimates the order with some probability, whereas HQ estimates the order consistently and SC is even strongly consistent (see, for example, Lütkepohl (2005)). For the sub-samples we use the same lag order.

5 Note our sample ends in 2006:4. See the Appendix for a description of the data. As most time series included in the VAR exhibits a stochastic trend we do not include a deterministic trend. A possible linear trend is picked up in the vector of constants.
} 
are seasonally adjusted, households' housing wealth, which covers the value of all dwellings including the value of land on which the buildings are constructed, is only available on a semi-annual basis and has therefore been interpolated (ECB (2006)). Data for the euro area has been obtained from an updated version of the Area-Wide Model data base by Fagan et al. (2001) and official ECB statistics. The US short-term interest rate is taken from the Federal Reserve Bank of St. Louis data base (FRED).

Figure 1: IRFs to monetary policy shock for the whole sample period (1980:1 2006:4)
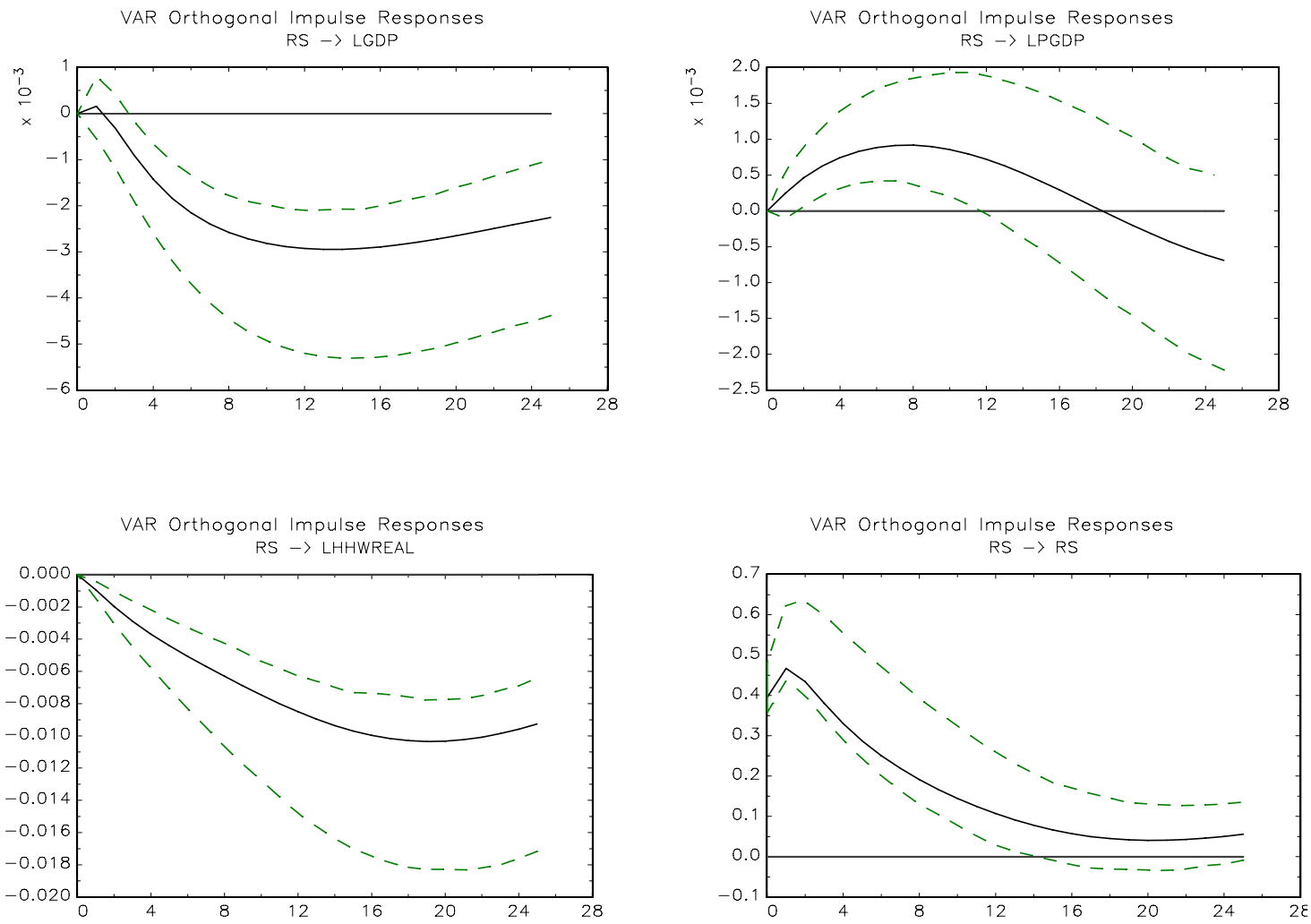

The dashed lines represent 95\% Hall (1992) percentile (1000 bootstrap replications).

Estimating the VAR over the whole sample period 1980:1 - 2006:4 and identifying monetary policy shocks as described yields the IRFs to monetary policy shocks displayed in Figure 1 (for the whole set of IRFs, see Weber, Gerke and Worms, 2008). The results, however, oppose economic theory and the "stylized facts" of monetary transmission. More specifically, a restrictive monetary policy shock reduces output in the long run and, 
therefore, runs counter the notion of long-run neutrality of monetary policy. In addition, monetary policy seems not to be able to pin down inflation in the long run since it appears unable to cause a significant long-run reduction of the price level. On the contrary, a quite persistent "price puzzle" is observed, that is, the increased interest rate goes (temporarily) hand in hand with a significantly higher price level (despite the inclusion of "standard" exogenous variables which according to earlier work should reduce or eliminate the "price puzzle”).

One possible reason for this unsatisfactory description of monetary transmission could be that the set of variables is insufficient or inadequate to describe macroeconomic dynamics in the euro area. The chosen set of endogenous and exogenous variables, however, is fairly standard in the literature, possibly with the exception of real housing wealth. ${ }^{6}$ Moreover, including additional variables such as a long-term interest rate and/or money does not change or improve the overall picture (see also Section 3.4 below). Another reason for the unsatisfactory results could be that the chosen identifying procedure is inappropriate. However, varying the order, using structural or agnostic identification schemes does not improve the results either. A third explanation for these unsatisfactory results could be that the euro area economy underwent significant structural changes over the sample period 1980 to 2006 which are not adequately captured by the estimated VAR.

\subsection{Searching for a possible single break date}

In order to check this possibility, we investigate the stability of the benchmark VAR by performing alternative break-point tests. We use test statistics applied to the individual equations of the benchmark VAR as well as to the complete vector model. For the vector model we apply two different types of Chow tests. Given that Chow tests may have distorted distributions relative to the asymptotic $\chi^{2}$ and approximate $F$ distributions in dynamic models we use a (system) bootstrap version of a sample-split and a break-point

6 Yet, including real housing wealth improves the overall fit of the model and proves to be an important explanatory variable for the euro area in other instances as well (see, e.g., the money demand analysis of Greiber and Setzer, 2007). 
Chow test as proposed by Candelon and Lütkepohl (2001). ${ }^{7}$ Basically, these tests compare the residual variance estimate from a constant parameter coefficient model with the residual variance estimate of a model that allows for a change in the parameters at a (single) given point in time. The tests are performed repeatedly for every quarter between 1984 and 2002 as potential break points. Figure 2 plots the bootstrapped $p$-values for the sample-split test applied to the baseline VAR.

\section{Figure 2: Sample-split Chow-test: bootstrapped $p$-values (1,000 replications)}

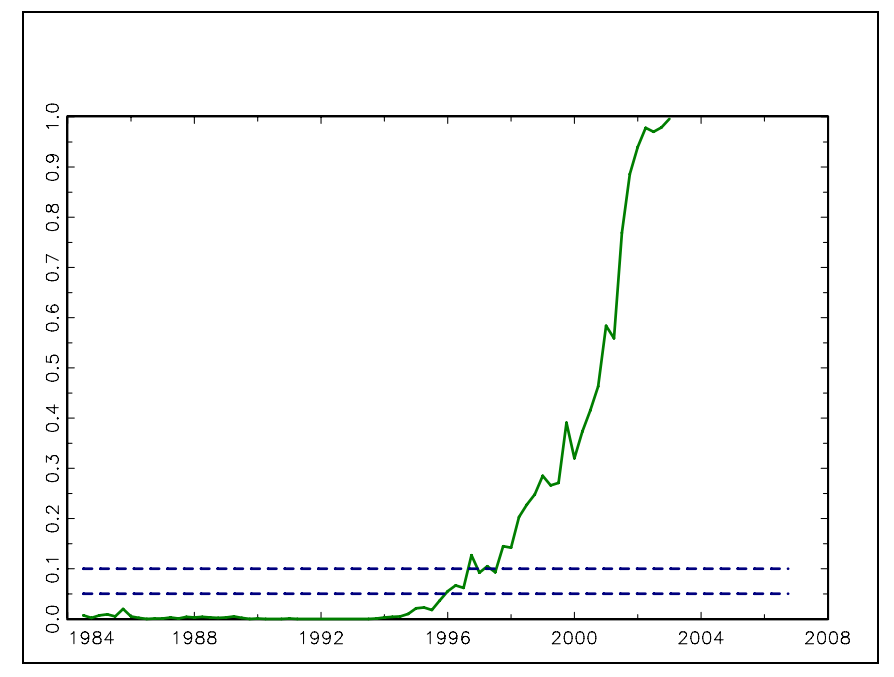

Obviously, the $p$-values remain below 5\% until 1996. From then on, they give rise to concerns regarding the stability of the model over the whole sample period. The null hypothesis of parameter constancy is generally rejected according to the break-point test which additionally checks the constancy of the white noise variance. Thus, it appears that not only the propagation of the VAR shocks has changed over the past decades but the variance of the innovations as well. As a complementary check we use the Ploberger, Krämer and Kontrus (1989) fluctuation test on an equation-by-equation basis. ${ }^{8}$ The idea behind this test is to reject the null hypothesis of parameter constancy whenever these estimates fluctuate too much. Unlike the Chow tests this test does not require that possible

\footnotetext{
7 As noted by Candelon and Lütkepohl (2001) it turns out that in samples of common size the $\chi^{2}$ and $F$ approximations of the actual distributions may be poor even if a single break point is tested. The actual rejection probabilities may be much larger than the desired type I error. For completeness we also apply a system 1-step Chow test as implemented in Doornik and Hendry (2007). This test indicates parameter instability for the mid 1990s, although somewhat earlier as indicated by the bootstrap versions.

8 We used Anders Warne’s program Structural VAR 0.40.
} 
break points are set ex ante. As in the case of the system Chow tests this test indicates parameter instability for the mid 1990s as well (Figure 3).

\section{Figure 3: Ploberger, Krämer and Kontrus fluctuation test (1989)}
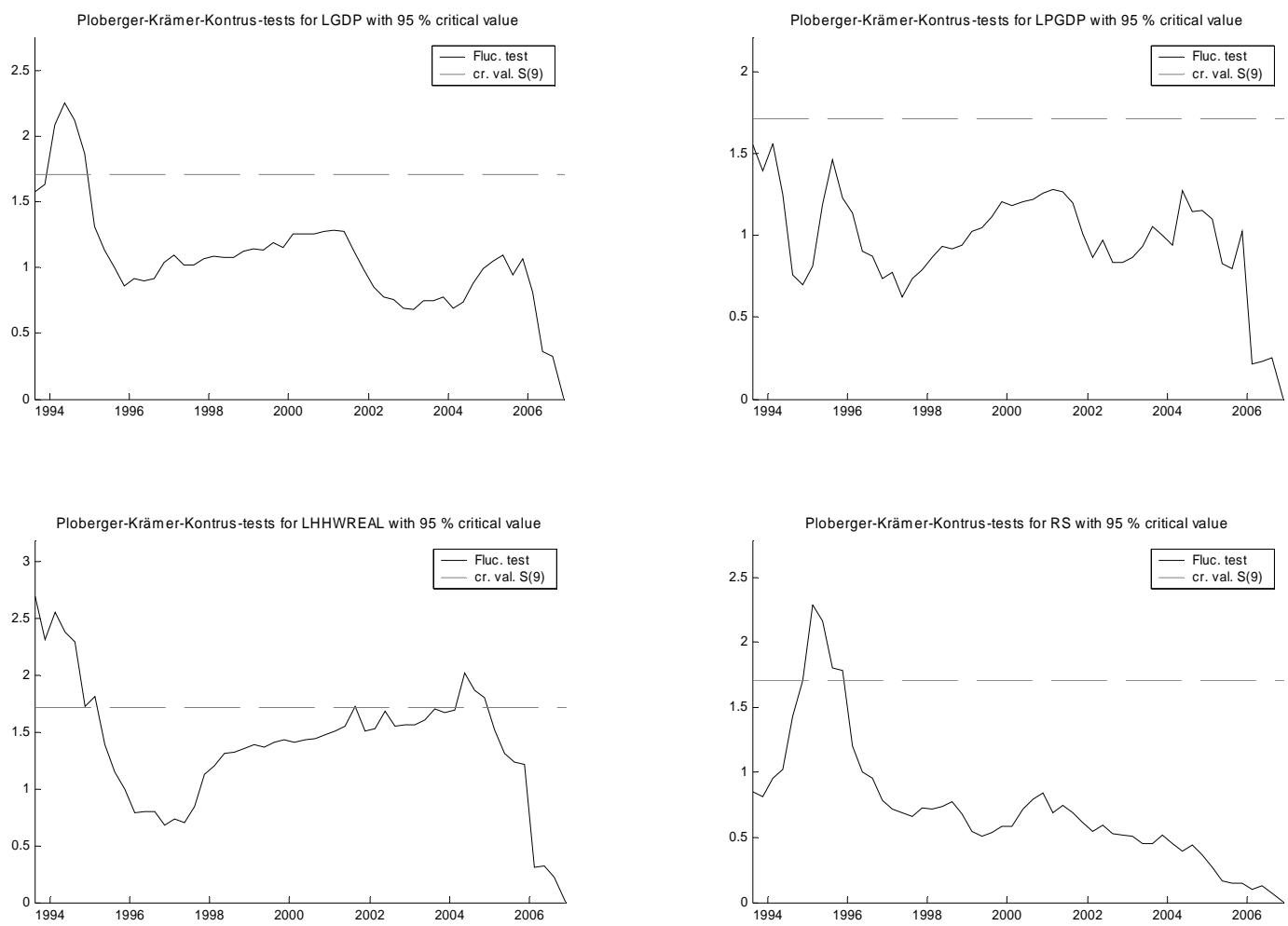

Taken together, we interpret the test results as strong evidence in favour of structural changes in the sample. ${ }^{9}$ Although the results of these different tests do not allow us to pin down the break date to a specific quarter they clearly indicate significant structural changes of the data generating process that might have occurred at least until 1996. ${ }^{10}$

\subsection{VAR estimations with a break in 1996}

We now examine whether or not theses changes have significantly affected the transmission of monetary policy shocks. We do so by comparing the IRFs of the

9 Note, to the extent that the true model of the economy is appropriately described by a linear model, potentially omitted variables do not generate spurious instability. A possible omission might bias the parameter estimates of the systematic component, but would not imply structural changes across samples (see also Boivin and Giannoni, 2002).

10 This interpretation, notably a break around the mid 1990s is consistent with the results in Breitung and Eickmeier (2008). 
endogenous variables of the benchmark VAR (especially output and prices) estimated over two sub-samples. Based on the test results we obtained so far, the first sub-sample is chosen to correspond to 1980:1-1996:1 and the second sub-sample corresponds to 1996:22006:4. When estimating the VARs only observations from the respective sub-sample are used, including the initial lags.

Figure 4: IRFs to monetary policy shock for the sub-sample 1980:1 - 1996:1
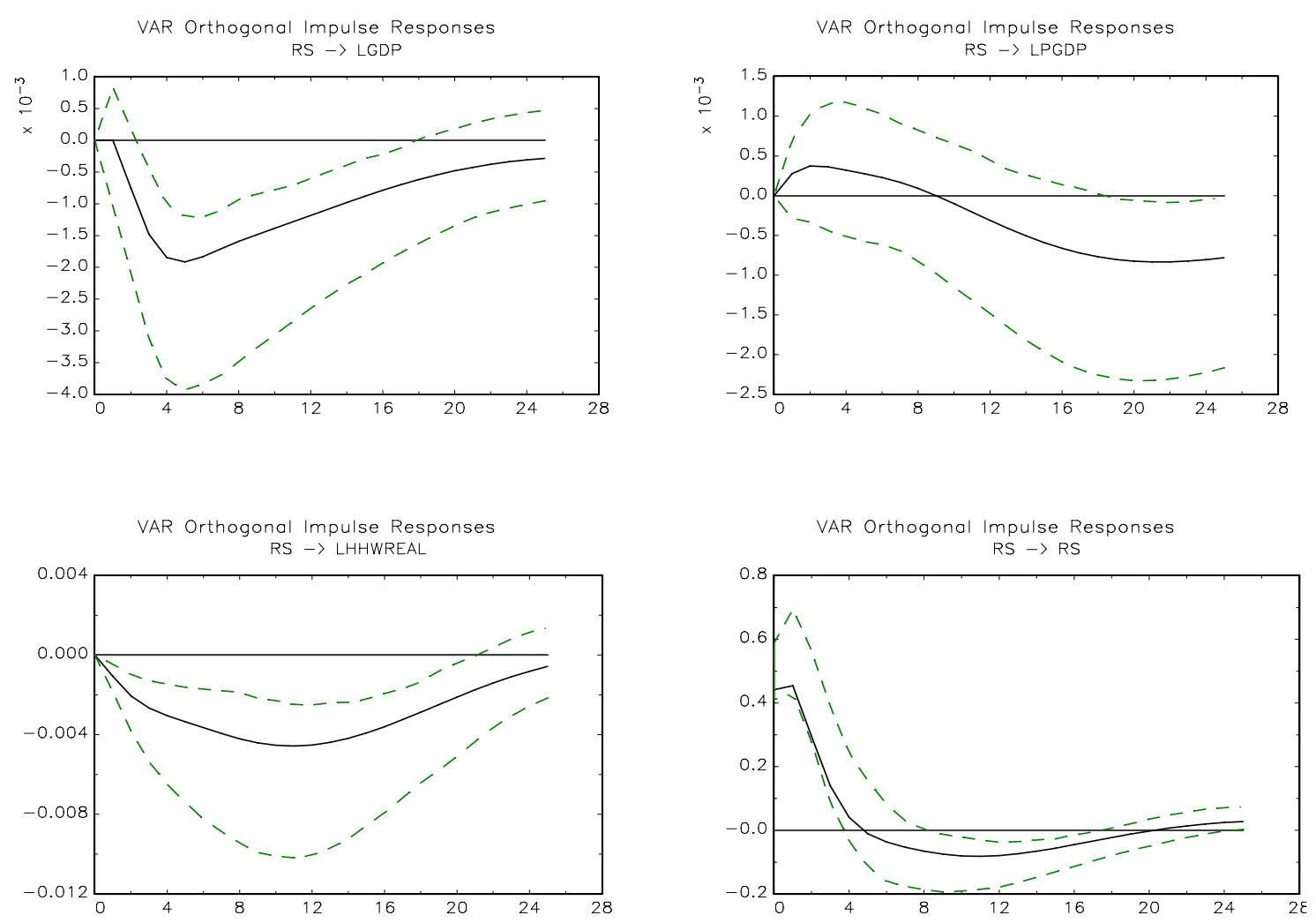

The dashed lines represent 95\% Hall (1992) percentile (1000 bootstrap replications).

Figure 4 displays the IRFs with respect to an unexpected increase in the short-term interest rate for the period 1980:1-1996:1 and Figure 5 the respective IRFs for 1996:22006:4. The following similarities and differences appear. Generally, in contrast to the IRFs for the whole sample period, the IRFs for both sub-periods now show a reasonable reaction of the endogenous variables to a restrictive monetary policy shock. More specifically, we observe long-run neutrality of monetary policy with respect to real GDP and a significant negative long-run reaction of the GDP deflator. In the long run, the short- 
term interest rate converges to its initial level. In the short run, we observe a significant contraction of output and a significant decrease of the GDP deflator, which is in line with both the previous empirical literature and with economic theory. ${ }^{11}$ Also in line with the empirical literature, the price reaction becomes significant only with a lag, that is, after GDP has already declined. A persistent "price puzzle” cannot be observed. Furthermore, real housing wealth decreases significantly in the short run in both sub-samples but returns (although slowly) to its initial level only in the first sub-sample.

Figure 5: IRFs to monetary policy shock for the sub-sample 1996:2 - 2006:4
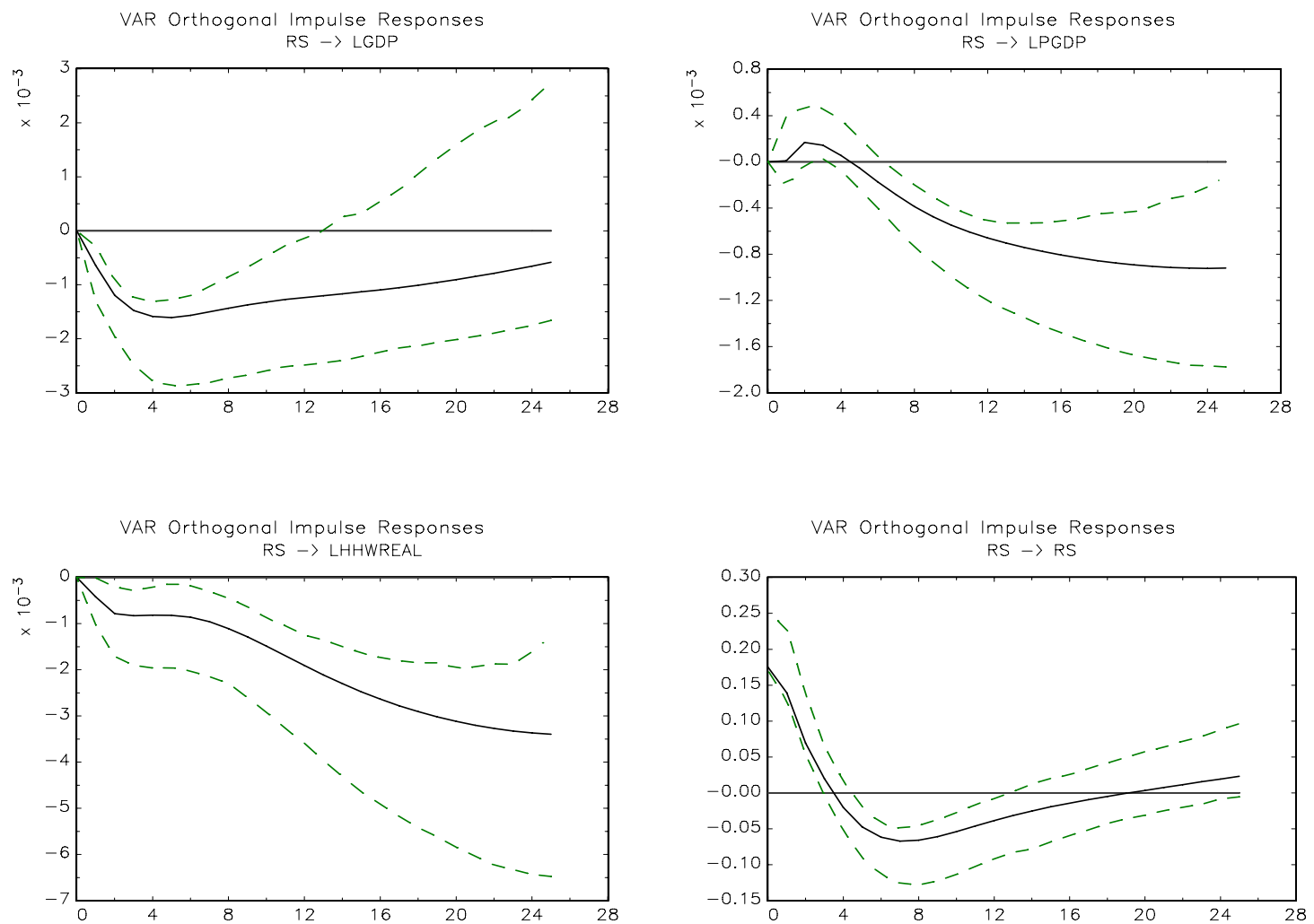

The dashed lines represent 95\% Hall (1992) percentile (1000 bootstrap replications).

11 The figure shows the effects of a one standard deviation monetary policy shock. If we assume a tightening of $100 \mathrm{bp}$, GDP falls about $0.5 \%$ after six quarters in the first sample and about $0.9 \%$ after six quarters in the second one. GDP deflator falls about $0.2 \%$ and $0.4 \%$ after four years, respectively. 
Figure 6: IRFs to monetary policy shock for the sub-sample 1980:1-1996:1 and for the sub-sample 1996:2-2006:4
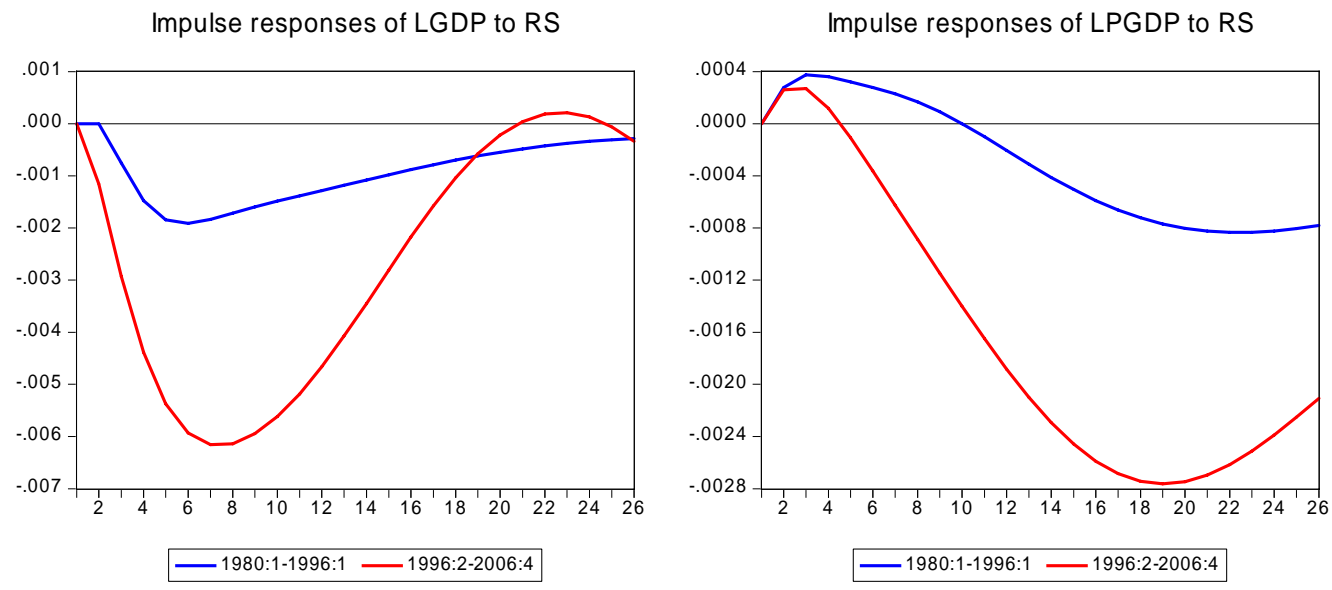

Impulse responses of LHHWREAL to RS

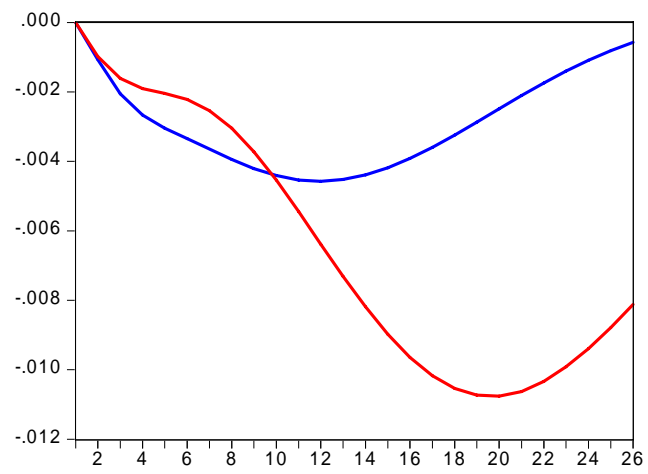

-1980:1-1996:1 -1996:2-2006:4

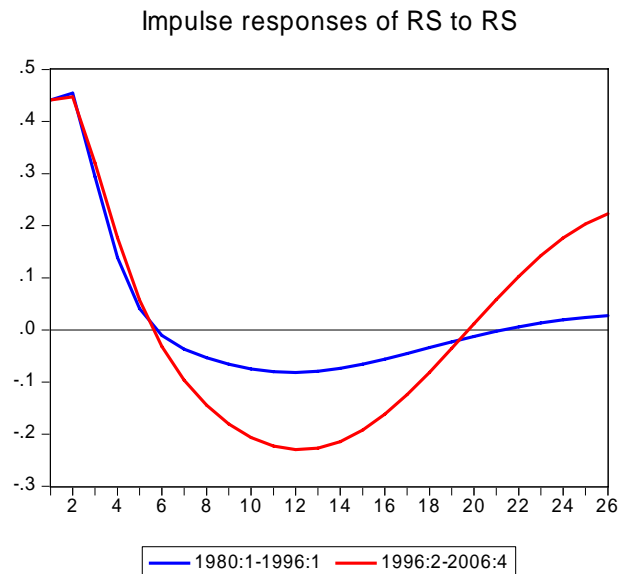

While these qualitative stylized facts of monetary transmission are captured by both sets of IRFs, a comparison seems to indicate a quantitative change (see Figure 6): ${ }^{12}$ after 1996 (red lines) real GDP seems to react faster and stronger to monetary policy while the GDP deflator appears to react stronger than before (blue lines). Moreover, the short-term interest rate reaction is more pronounced and the short-term reaction of real household wealth appears stronger after 1996. A persistent negative reaction of housing wealth can be detected in the second sub-sample, which is not present in the first. Finally, the

${ }^{12}$ For the sake of comparability, we impose in Figure 7 the monetary shock to be of the same size in both sub-samples. Technically, the impulse responses have been obtained by estimating an extended version of the baseline VAR that includes a vector of dummy variables. These dummy variables take the value zero for the period 1980:1-1996:1 and the value one for the period 1996:2-2006:4. In addition we applied a "general-to-specific" procedure to get a more parsimonious model. However, in comparison to an unrestricted version of the baseline model this procedure does not seem to have a notable effect on the IRFs. 
standard deviation of the monetary shock in the second sub-sample is about half the size compared to the first sub-sample. All in all, the IRFs in the second sample period appear more pronounced and more persistent. ${ }^{13}$

\subsection{Sensitivity analysis and robustness checks}

In order to check robustness of these results we vary the econometric setup of our empirical exercise. Specifically, we examine the effects of using alternative break points and different econometric specifications of the VAR. Regarding the latter, we estimate a battery of IRFs based on variations of our baseline VAR with additional lags, additional variables or different shock identification schemes. Moreover, we estimate some VAR models not nested in the (augmented) baseline VAR.

- $\quad$ Adding (the log of) M3 or a long-term interest rate does not change the key results. Specifically, we find evidence for significant break points in the sample. Not surprisingly, the exact date of this break point varies somewhat with the specification, but in most cases break points are detected until the mid 1990s or somewhat later.

- $\quad$ Using an alternative commodity prices index, substituting CPI (HICP) for GDP deflator, substituting house prices for housing wealth or estimating the variables in differences does not yield notable different insights.

- $\quad$ Using two VAR specifications of Peersman and Smets (2003) that are not nested in our (augmented) benchmark VAR we reproduce our key results. Specifically, when excluding housing wealth and including a real exchange rate instead, we get break points around the mid 1990s and the IRFs in the second sub-sample appear, once again, more pronounced.

Shifting the break point of the two sub-samples between 1990 and 1998 yields qualitatively similar results as well. In particular, the evidence of stronger impulse responses of output and household wealth in the second sub-sample seems not to depend on a specific split date. In the same vein, starting the sample in 1984 does not yield any

\footnotetext{
13 In Weber, Gerke and Worms (2008) we show that theses differences are indeed statistically different from
} zero. 
noteworthy new insights. ${ }^{14}$ This conclusion, however, does not hold if we allow the second sub-sample to start as late as 1999. Then, the IRFs turn out to be smaller in the second sub-sample than in the first even if we control for the reduced size of the monetary policy shock. This "switch" is robust to augmenting the VAR by additional variables, i.e. assuming a single break point in 1999 turns our results upside down. Interestingly, this is in line with Boivin, Giannoni and Mojon (2008) who use a factor-augmented VAR to check whether the introduction of EMU has led to changes in monetary transmission and find that the effects of monetary policy shocks on key macroeconomic variables have become smaller after 1999 compared to the pre-1999 period. The fact that we can replicate this result is remarkable since it indicates that the use of our small set of variables does not necessarily imply a major loss of important information. ${ }^{15}$ Instead, it shows the key role regarding the "choice" of a specific break point: With a break point in 1996, we find that monetary transmission has strengthened, with a break point only three years later, we find the opposite.

\subsection{Another break?}

Up to now, we (implicitly) assumed only one notable structural change and an associated break in monetary transmission which was endogenously determined to lie around 1996 (or earlier). ${ }^{16}$ This is surely a simplification since structural relationships most likely do not change dramatically from one quarter to another but rather take a more or less extended "transition” period. ${ }^{17}$ Moreover, we cannot rule out that another notable break or change occurred during the sample period.

14 There is some evidence that the mean of consumer price inflation has changed in the mid 1980s (see Altissimo, Ehrmann and Smets, 2006). Note, our results do not dependent on the aggregation method used for the euro area data. Specifically, if we construct euro area GDP and the euro area GDP deflator with flexible exchange rates does not have a notable effect.

15 Yet, the use of factor-augmented VARs is not without problems as it might produce "spurious results", see Uhlig (2008).

16 Such a break point is reasonable from an economic point of view. For instance, in the euro area the exchange rate became unavailable as a monetary policy tool already around 1995. If one takes it for granted that we have witnessed at least one such notable change it is not too surprising that our estimates for the whole sample do not appear fully satisfactory.

17 The documented change in the relative strength of monetary policy is unlikely to have happened at a specific date. For instance, as regards EMU the fact that monetary regimes in Europe would change on January 1, 1999 was well known before. Hence, agents likely started to prepare quite some time before that event. Further, it is reasonable to assume that these preparations for adjustment were stretched over several years. 
However, given the short remaining time span, it is difficult to detect such an additional break point or an interim period with statistical methods (alone). As our Chow tests have already identified a break point in 1996 (and not later), it might be difficult to detect an additional (subsequent) break as the period up to 1999 covers only three additional years. In the following, we therefore take an indirect approach to assess whether there could have been another break point around 1999 or an interim period from 1996 to 1999. More specifically, we re-estimate an extended VAR with two different types of interaction terms (controlling for 1996-1998 and 1999-2006 separately) and calculate the IRFs for the first (1980-1996) and the third sub-period (1999-2006). If the IRFs for 19801996 and 1999-2006 are not significantly different from each other - given our previous result of significantly different IRFs for 1980-1996 and 1996-2006 - this could be interpreted as another break point around 1999 or likewise of an "atypical” interim period between 1996 and 1999.

Technically, we re-estimate an extended version of the baseline VAR that includes two vectors of dummy variables. The dummy variables of the first vector take the value one for the period 1996:1-1998:4 and the value zero otherwise: the dummy variables of the second vector take the value zero for the period 1980:1-1998:4 and the value one for the period 1999:1-2006.4:

$$
\begin{aligned}
& d_{t}^{1}= \begin{cases}0 & \text { for } 1980: 1 \leq t \leq 1995: 4 \text { and } 1999: 1 \leq t \leq 2006: 4 \\
1 & \text { for } 1996: 1 \leq t \leq 1998: 4\end{cases} \\
& d_{t}^{2}= \begin{cases}0 & \text { for } t<1999: 1 \\
1 & \text { for } t \geq 1999: 1\end{cases}
\end{aligned}
$$

We allow these dummy variables to interact with all lags of the endogenous and the (contemporaneous) exogenous variables:

$$
y_{t}=k+A(L) y_{t-1}+B x_{t}+C^{1}(L) d_{t}^{1} y_{t-1}+D^{1} d_{t}^{1} x_{t}+C^{2}(L) d_{t}^{2} y_{t-1}+D^{2} d_{t}^{2} x_{t}+u_{t} .
$$

As equation (5) illustrates, the coefficients on the lagged endogenous variables are equal to $A(L)$ for the period 1980:1 to $1995: 4$ and, for instance, $A(L)+C^{2}(L)$ for 1999:1 to 2006:4; for the exogenous variables the coefficients are accordingly $B$ and $B+D^{2}$, respectively. 
Figure 7: IRFs to monetary policy shock for the sub-sample 1980:1-1996:1 and for the sub-sample 1999:1-2006:4
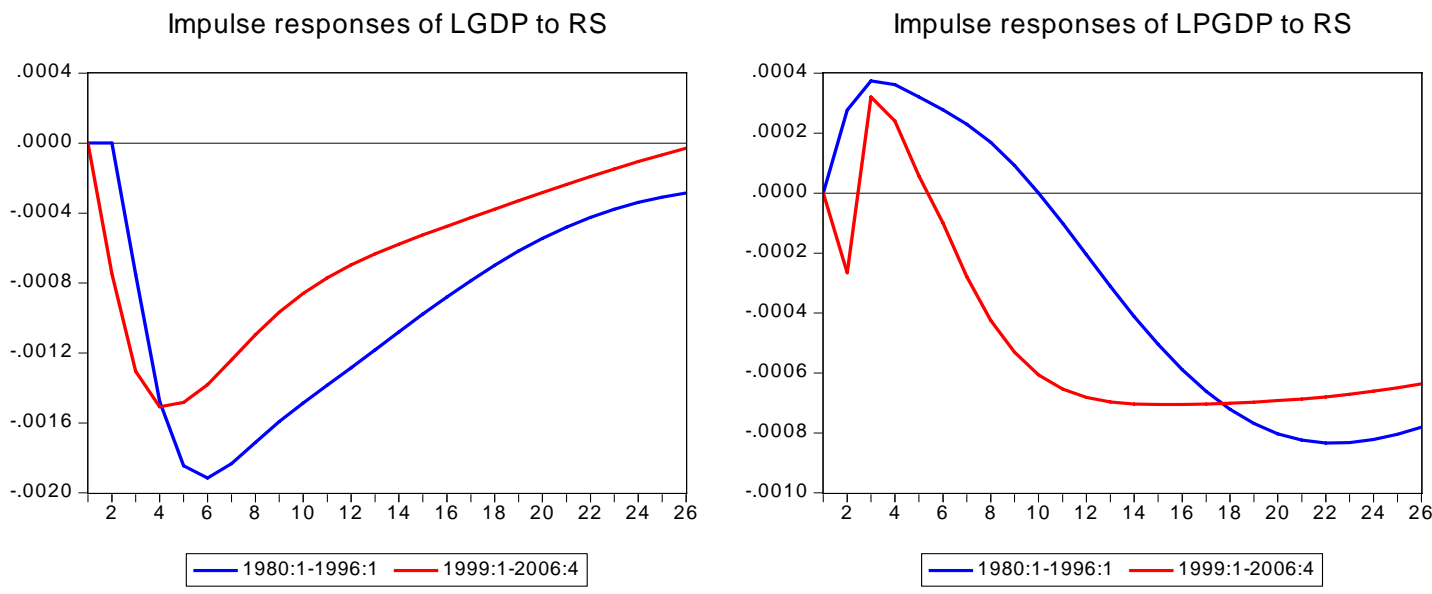

Impulse responses of LHHWREAL to RS

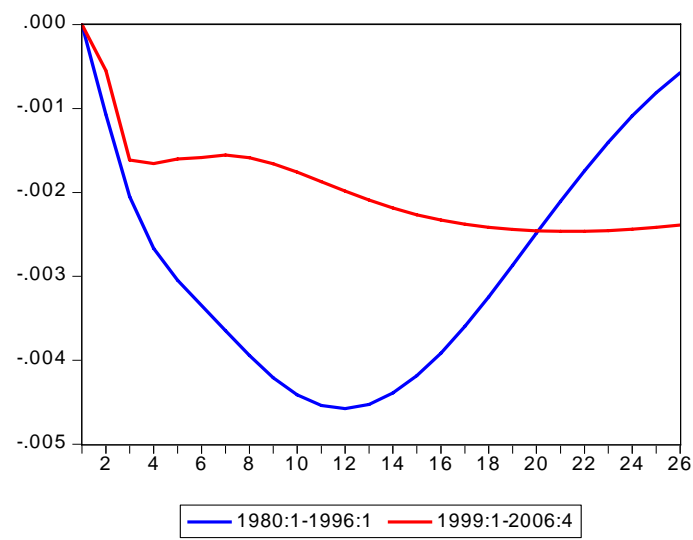

Impulse responses of RS to RS

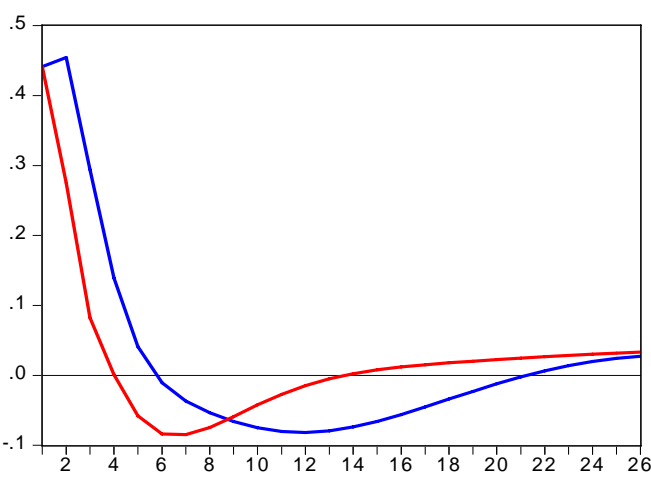

-1980:1-1996:1 -1999:1-2006:4

Figure 7 shows the IRFs resulting from the extended VAR and highlights that both the IRFs for the first period 1980:1-1996:1 and for the third period 1999:1-2006:4 appear quite similar (relative to the differences in Figure 6) - maybe with the exception of the response of housing wealth. In order to check whether these differences are significantly different from zero we apply the following bootstrap procedure: We first estimate equation (5), compute the IRFs for the respective sub-periods and take the difference between them. We then generate bootstrap residuals by randomly drawing them with replacement from the estimated residuals of the complete sample. Subsequently, the residuals are used to recursively compute bootstrap time series under the null hypothesis of parameter constancy. ${ }^{18}$ Then, equation (5) is re-estimated based on the bootstrap time series and the

18 The bootstrap procedure implicitly assumes that the standard deviations of the VAR residuals do not change over time. 
respective IRFs are calculated (again). ${ }^{19}$ For every such bootstrap-iteration the difference between the respective IRFs is calculated. Repeating this many times yields an empirical bootstrap distribution of the difference of the IRF which we use to derive confidence intervals for the differenced IRFs. Figure 8 displays the differences between these IRFs together with a 95\% confidence band and illustrates that none of the differences appear statistically significant, i.e. they do not deviate significantly from zero. Thus, it appears that the IRFs for the first and the third sub-period portray a similar monetary policy transmission. Or, to put it differently, there is (indirect) evidence in favour of an "atypical" interim period from 1996:1 - 1998:4 which lies between two more or less similar regimes. Of course, given the short time span from 1999-2006 we should interpret this result with great care.

Figure 8: Differences between IRFs of the first sub-sample (1980:1-1996:1) and the third sub-sample (1999:1 - 2006:4) with 95\% confidence interval
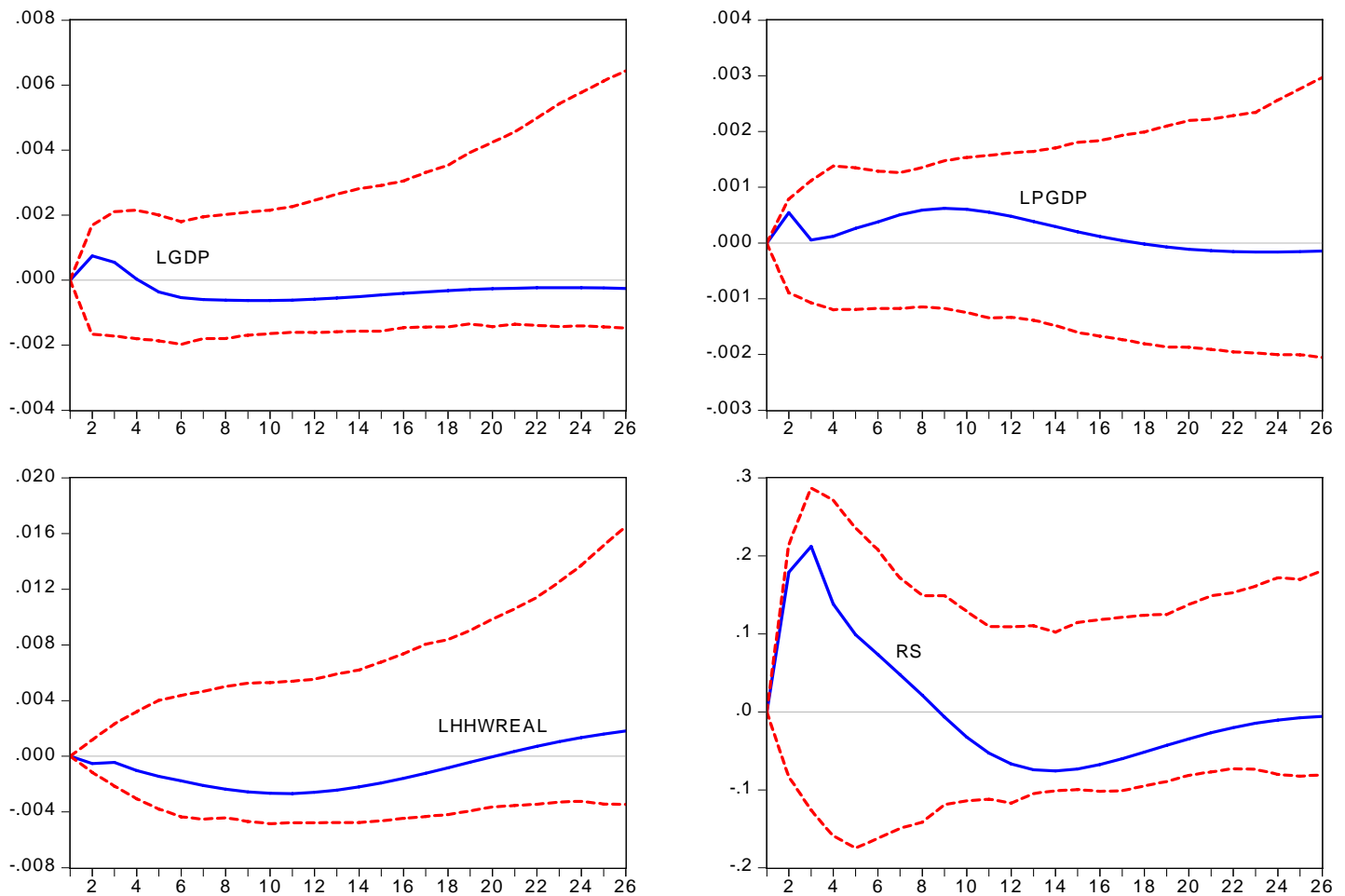

The dashed lines represent 95\% standard percentile (1000 bootstrap replications).

19 Note, under the null hypothesis of parameter constancy the respective impulse response functions should differ only randomly. 
Taken at face value, this evidence is compatible with the view that - in the end - the monetary transmission process in the euro area has not changed tremendously: The IRFs for the first period 1980-1996 do not differ notably from those for the third period 19992006, while monetary policy seems to have worked very differently in the interim period. Due to data limitations, however, it is not possible to pin down how the monetary transmission process looked like in that period, but it seems plausible that transmission was faster and stronger than in the other sub-samples. This conclusion basically relies on the observation that by assuming only one break point and merging the interim period with the first sub-period, the IRFs indicate that transmission became weaker; but if we merge the interim phase with the later sub-period, then the results point to a faster and stronger transmission.

A strong caveat remains. One has to keep in mind that all empirical work on the euro area data still suffers from the fact that it relies on rather short time series. At the end of the day, we therefore cannot rule out that the two periods 1980-1996 and 1999-2006 might better characterised by two different regimes displaying two genuine different transmission processes, so that the "interim period" is more a "transition period" that carries one regime over to the next one.

\section{Summary of results and conclusions}

We would like to summarise our main findings as follows:

(1) Euro area monetary transmission has undergone notable changes in the mid 1990s; specifically, there is evidence for a structural break occurring around 1996 and possibly a second one around 1999. Estimating a canonical VAR for the whole sample period without controlling for (at least) one of these breaks significantly distorts the estimates.

(2) These changes of the monetary transmission process have not altered the long-run responses of real output and inflation to monetary policy: long-run neutrality holds and monetary policy is able to control inflation in the long-run. 
(3) Overall, monetary transmission for 1980-1996 is not significantly different from that for 1999-2006. ${ }^{20}$ This might be interpreted as evidence in favour of an "atypical” interim period characterized by “perturbations” lasting from 1996 to 1999. However, given data limitations we cannot rule out that the period 1996 to 1999 characterizes a transition period “connecting” one regime with another (new) one.

These results turn out to be robust against a broad range of variations.

Our endogenously-determined break point in 1996 and the possible interim period 1996-1999 are in principle compatible with all three driving factors that we have discussed in the introduction of this paper. As concerns the timing, EMU as well as globalisation and financial innovation could have been crucial for the changes we have documented.

However, it is striking that the timing we find by conducting a data-driven analysis is very much in line with the hypothesis that the run-up to EMU has caused "perturbations" or "adjustments" in the data which seem to disappear afterwards. With convergence already starting well before 1999, the joint dynamics of key macro variables in single euro area countries and therefore also in the euro area as a whole might have been different from earlier periods. ${ }^{21}$ That - together with other the other factors already mentioned - could have been decisive for a "break point" well before 1999. The fact that we also find (weaker) evidence for another break date around 1999 points to the possibility that this period of EMU convergence phased-out with the launch of the euro. Whether the system then really returned to its "previous" structure or whether we are in a new state compared to the pre-convergence period remains an open question. For the time being, our analysis does not suggest significant differences in the IRFs.

We find this latter result reassuring since it indicates that our (prior) knowledge about monetary transmission remains useful, despite (or better: because of) the break points we found. Especially, our estimates stress that - for all sub-periods - monetary policy ultimately affects prices, but not real activity. Therefore, one of the cornerstones of the Eurosystem's monetary policy strategy, that is, giving price stability clear priority as the goal of monetary policy, was and is still well justified: In the long-run, monetary

20 The same is true if we start our sample in 1984 and compare 1984-1996 with 1999-2006.

${ }^{21}$ In a certain sense, this specific interim period is similar to other periods that have been scrutinized from a monetary policy point of view. Specifically, the interim regime 1996-1998 witnessed similar patterns of disinflation as the time spans after the appointment of Paul Volcker in the United States and the period following the decision of Deutsche Bundesbank to switch to monetary targeting. 
policy can - and should - anchor inflation and inflation expectations at low levels, but it cannot - and should not - (try to) foster (unsustainable) output growth. This is clearly good news.

This positive assessment applies to the two pillars of the Eurosystem monetary policy strategy as well. Our finding that breaks or an interim period occurred just illustrates that monetary policy always faces considerable uncertainty about the true structure of the economy, about its state and about the impact monetary policy exerts on it (see, for instance, Walsh, 2003). At the end of the day we should keep in mind the recommendations of the growing literature on "monetary policy under uncertainty": Monetary policy should not concentrate on a too narrow set of indicators when judging the monetary policy stance or when making monetary policy decisions (see e.g. Deutsche Bundesbank, 2004). Here, the monetary policy strategy of Eurosystem is well suited, since - within its two pillars - it regularly looks at a broad range of indicators for inflationary pressures and takes both, "real” and "monetary" models of inflation into account.

\section{REFERENCES}

Altissimo, F., Ehrmann, M., Smets, F., 2006. Inflation Persistence and Price Setting Behaviour in the Euro Area. ECB Occasional Paper Series, 46.

Assenmacher-Wesche, K., Gerlach, S., 2008. Ensuring Financial Stability: Financial Structure and the Impact of Monetary Policy on Asset prices. Mimeo.

Ball, L., 2006. Has Globalization changed Inflation? NBER Working Paper Series, 12687.

Boivin, J., Giannoni, M., 2002. Assessing Changes in the Monetary Transmission Mechanism: A VAR Approach. Federal Reserve Bank of New York, Economic Policy Review, 8, 97-112.

Boivin, J., Giannoni, M., Mojon, B., 2008. Macroeconomic Dynamics in the Euro Area. Mimeo.

de Bondt, G., 2005. Interest Rate Pass-through: Empirical Results for the Euro Area. German Economic Review, 6 (1), 37-78.

de Bondt, G., Mojon, B., Valla, N., 2005. Term Structure and the Sluggishness of Retail Bank Interest Rates in Euro Area Countries. ECB Working Paper Series, 518.

Borio, C., Filardo, A., 2007. Globalisation and inflation: New cross-country evidence of the global determinants of domestic inflation. BIS Working Papers, 227.

Borio, C., Zhu, H., 2007. Capital Regulation, Risk-taking and Monetary Policy: A Missing Link in the Transmission Mechanism? Paper presented at the conference on "The Implications of Changes in Banking and Financing on the Monetary Policy Transmission”, ECB, Frankfurt, 28-29 November. 
Breitung, J., Eickmeier, S., 2008. Testing for structural breaks in dynamic factor models. Mimeo.

Calza, A., 2008. Globalisation, Domestic Inflation and Global Output Gaps. ECB Working Paper Series, 890.

Candelon, B., Lütkepohl, H., 2001. On the reliability of Chow-type tests for parameter constancy in multivariate dynamic models. Economic Letters 73, 155-160.

Cournède, B., Ahrend, R., Price, R. 2008. Have long-term financial trends changed the transmission of monetary policy? OECD Working Paper, ECO/WKP(2008)42.

Deutsche Bundesbank, 2004. Monetary Policy under Uncertainty. Monthly Report, June 2004, 15-27.

Deutsche Bundesbank, 2007. Globalisation and Monetary Policy. Monthly Report, October 2007, 15-33.

Doornik, J.A., Hendry, D.F., 2007. Modelling Dynamic Systems - PCGive ${ }^{\mathrm{TM}} 12$ : Volume II, Timberlake Consultants Ltd.

European Central Bank, 2006. ECB estimates of Euro Area Capital Stock and Household's Housing Wealth. Mimeo.

Ehrmann, M., Worms, A., 2004. Bank networks and monetary policy transmission. Journal of the European Economic Association 2(6), 1148-1171.

Fagan, G., Henry, J., Mestre, R., 2001. An area-wide model (AWM) for the euro area. ECB Working Paper, 42.

Greiber, K., Setzer, R., 2007. Money and housing - evidence for the euro area and the US. Deutsche Bundesbank, Discussion Paper Series 1, 12/2007.

Gropp, R., Sørensen, C.K., Lichtenberger, J.D., 2007. The Dynamics of Bank Spreads and Financial Structure. ECB Working Papers, 714.

Hall, P., 1992. The Bootstrap and Edgeworth Expansion. Springer-Verlag, New York.

Iacoviello, M., 2005. House Prices, Borrowing Constraints, and Monetary Policy in Monetary Policy in the Business Cycle. American Economic Review, 95(3), 739-764.

Ihrig, J., Kamin, J.D., Lindner, D., Marquez, J., 2007. Some Simple Tests of the Globalization and Inflation Hypothesis. Board of Governors of the Federal Reserve System, International Finance Discussion Papers, 891.

Ihrig, J., Marazzi, M., Rothenberg, A.D., 2006. Exchange-Rate Pass-Through in the G-7 countries. Board of Governors of the Federal Reserve System, International Finance Discussion Papers, 851.

van Leuvensteijn, M., Sørensen, C.K., Bikker, J.A., van Rixtel, A.A.R.J.M., 2008. Impact of bank competition on the interest rate pass-through in the euro area. Tjalling $\mathrm{C}$. Koopmans Research Institute, Discussion Paper Series, 08.

Lütkepohl, H., 2005. New Introduction to Multiple Time Series Analysis. Springer Verlag, Berlin.

Mishkin, F., 2008. Globalization, Macroeconomic Performance, and Monetary Policy. NBER Working Paper Series, 13948.

Musso, A., Stracca, L., van Dijk, D., 2007. Instability and Nonlinearity in the Euro Area Philips Curve, ECB Working Paper Series, 811. 
Pain, N., Koske, I., Sollie, M., 2006. Globalisation and Inflation in the OECD Economies. OECD Working Paper, ECO/WKP(2006), 524.

Peersman, G., Smets, F., 2003. The monetary transmission mechanism in the euro area: evidence from VAR analysis”, In: Angeloni, I., Kashyap, A.K., Mojon, B. (Eds.), Monetary Policy Transmission in the Euro Area, Cambridge University Press, pp. 36-55.

Ploberger, W., Krämer, W., Kontrus, K., 1989. A New Test for Structural Stability in the Linear Regression Model. Journal of Econometrics, 40, 307-318.

Sbordone, A.M., 2007. Inflation persistence: Alternative interpretations and policy implications. Journal of Monetary Economics, 54, 1311-1339.

Uhlig, H., 2005. What are the effects of monetary policy on output? Results from an agnostic identification procedure. Journal of Monetary Economics, 52, 381-419.

Uhlig, H., 2008. Discussion of Macroeconmic Dynamics in the euro area by Boivin, J., Giannoni, M., Mojon, B., 2008.

Upper, C., Worms, A., 2003. Real long-term interest rates and monetary policy: A crosscountry perspective. In: BIS (Ed.): Monetary policy in a changing environment, BIS Papers 19, pp. 234-257.

Walsh, C., 2003. Implications of a Changing Economic Structure for the Strategy of Monetary Policy, In: Federal Reserve Bank of Kansas City (Ed.), Monetary Policy under Uncertainty: Adapting to a Changing Economy.

Weber, A.A., Gerke, R., Worms, A., 2009. Has the monetary transmission process in the euro area changed? Evidence based on VAR estimates. BIS Working Papers 276.

Woodford, M., 2007. Globalization and Monetary Control. Paper prepared for the NBER Conference on International Dimensions of Monetary Policy. 


\section{APPENDIX}

Figure A1: Time series included in the VAR analysis

LGDP

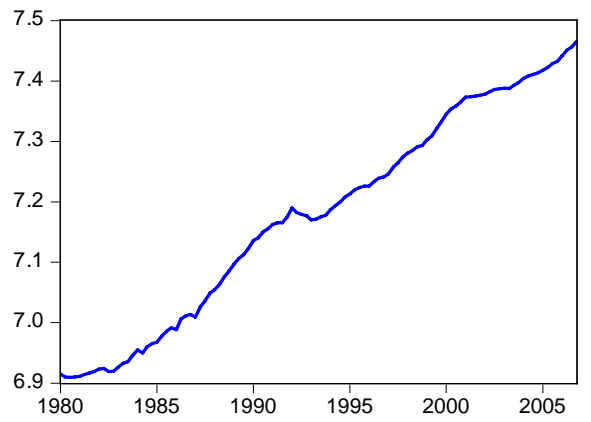

LHHWREAL

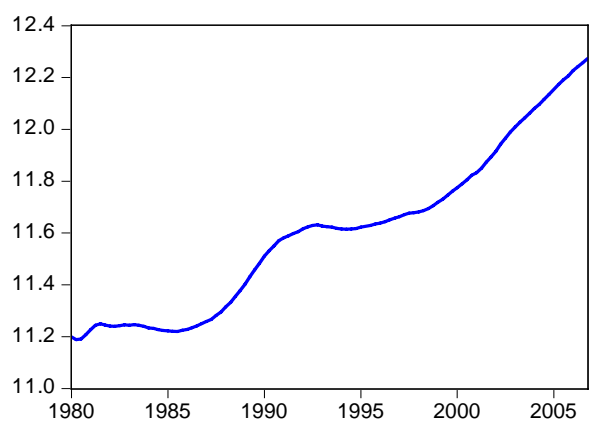

LPCM

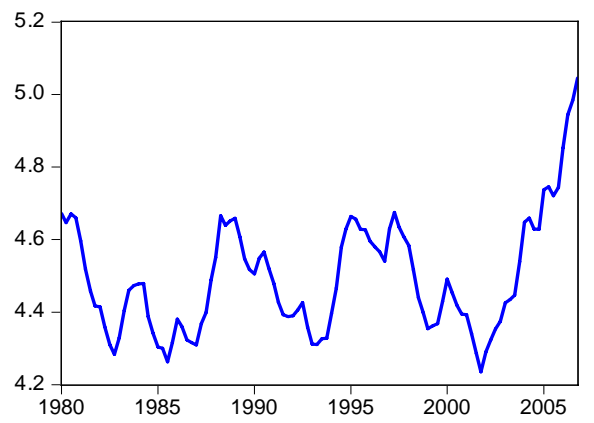

LPGDP

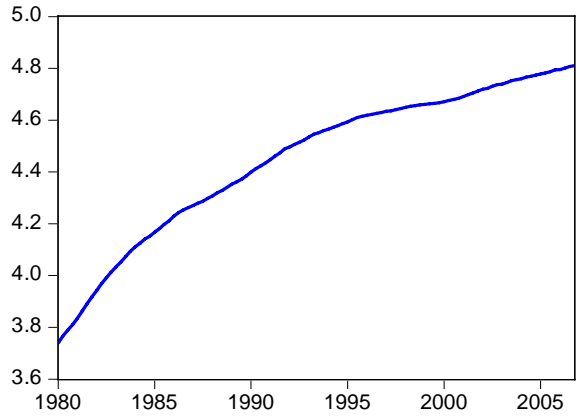

RS

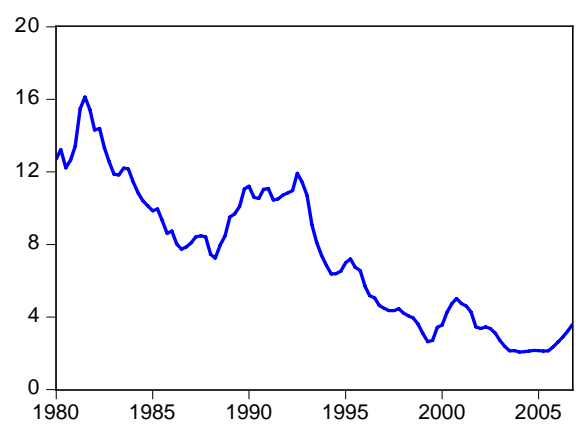

USRS

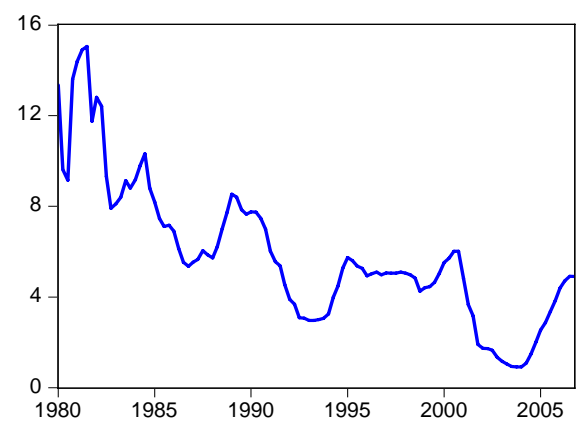

LGDP: $\quad$ log of real GDP (seasonally adjusted, AWM data base)

LPGDP: $\quad$ log of GDP deflator (seasonally adjusted, AWM data base)

LHHWREAL: log of households's housing wealth (interpolated, ECB (2006))

RS: short-term interest rate (AWM data base)

LPCM: log of non oil commodity prices (AWM data base)

USRS:

US short-term interest rate (Federal Reserve Bank of St. Louis data base) 